\title{
Prevalence of Tobacco Use in University Public Employees and Evaluation of Their Knowledge, Attitudes and Behaviors on This Subject
}

\author{
(1) Kamile Marakoğlu, (1) Gülbahar Ürün Ünal \\ Department of Family Medicine, Selçuk University Faculty of Medicine, Konya, Turkey
}

\section{ABSTRACT}

Objectives: In this study, we aimed to investigate the factors related to tobacco and cigarette smoking status, knowledge, attitudes, and behaviors of public employees of the Selçuk University.

Methods: This study was planned to determine the frequency of use of tobacco and its products and the attitudes and behaviors of 458 public employees of the Selçuk University between 2017 and 2018. A questionnaire consisting of 39 questions including the factors affecting the use/cessation status of tobacco and its products and the knowledge, attitudes, and opinions of the public employees of the university was applied.

Please cite this article as: Marakoğlu K, Ürün Ünal G. Prevalence of Tobacco Use in University Public Employees and Evaluation of Their Knowledge, Attitudes and Behaviors on This Subject. Anatol J Family Med 2019;2(2):58-67.

Address for correspondence: Dr. Kamile Marakoğlu. Department of Family Medicine, Selçuk University Faculty of Medicine, Konya, Turkey

Phone: +90 3322415000

E-mail: kmarakoglu@yahoo.com

Received Date: 02.11 .2018

Accepted Date: 22.02 .2019

Published online: 25.07 .2019

CCopyright 2019 by Anatolian Journal of Family Medicine Available online at www.anatoljfm.org

OPEN ACCESS

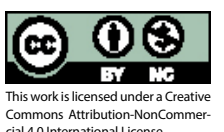

Results: The mean age of the 458 people studied was $39.21 \pm 10.26$; of them, $64.6 \%$ were males and $35.4 \%$ were females. In general, the frequency of using tobacco and smoking was $32.1 \%$. Among the university public employees, the frequency of tobacco and cigarette smoking status of medical faculty teaching staff and research staff was $23.2 \%$ and that of medical faculty nurses and other health staff was $38.0 \%$. Tobacco and cigarette smoking in males (38.2\%) was statistically significantly higher than in females $(21.0 \%)(p=0.000)$. The smoking rate was $26.6 \%$ and the smoking prevalence among medical faculty members (17.9\%) was lower compared to those of other health professionals $(35.4 \%)$ and academic staff $(26.0 \%)(p=0.053)$. Among the university employees, the smoking rate in males (33.1\%) was statistically significantly higher than in females (14.8\%) $(p=0.000)$. The frequency of narghile use was $11.1 \%$, hand-rolled tobacco use $7.0 \%$, cigar use $6.1 \%$, pipe use $1.5 \%$, and chewing tobacco use $0.4 \%$.

Conclusion: The fact that the frequency of using tobacco and cigarette is $32.1 \%$ and the cigarette smoking rate is $26.6 \%$ among the university public employees in our study reveals that tobacco and cigarette use is still a great problem.

Keywords: Patient education as topic, physician's role, physician-patient relations, smoking cessation

\section{INTRODUCTION}

Tobacco use and smoking is one of the most important and preventable public health issues around the world. Smoking is the most common form of tobacco use $(94.8 \%$ of all tobacco uses). ${ }^{[1]}$ Passive and active smoking cause psychological and financial losses, morbidities, and mortalities. According to World Health Organization data, 1.3 billion people around the world use cigarettes. Around the world, 1.5 billion people (one out of every three adults) aged 15 and over are addicted to tobacco and $80 \%$ of them are in developing countries. Of these 1.1 billion people who smoke above the age of 15, about 800 million live in developing countries. ${ }^{[2]}$ Six million people die annually due to tobacco-related diseases around the world and 
tobacco use leads to more than half a trillion dollars of economic damage. ${ }^{[3]}$ This means that in every 13 seconds, one person dies due to the use tobacco and its products across the world. WHO estimates that if the current situation is not changed, 20 million people would lose their lives in the early 2030 s, $70 \%$ of which will be from developing countries. ${ }^{[2]}$

Turkey is one of the leading countries in tobacco production and consumption. Turkey is among the top 10 in the list of countries with high prevalence of tobacco consumption. According to 2001 data, tobacco consumption in Turkey constitutes $2 \%$ of the world tobacco consumption and $14 \%$ of the WHO European Region tobacco consumption. ${ }^{[4]}$ As of 2008, approximately 16 million people in Turkey, 4 million women and 12 million men, are smokers and it is estimated that approximately 100 thousand people will die due to smoking each year and this number is expected to reach 240 thousand in $2030{ }^{[5]}$ According to conclusions of the PIAR study in 1998, prevalence of smoking among adults in Turkey is $24.3 \%$ for women and $62.8 \%$ for men. In addition, according to the 2003 National Burden of Disease study, the prevalence of smoking among men over 18 years of age was $51 \% .^{[6]}$

According to the Global Adult Tobacco Survey (GATS) conducted in Turkey in 2008, 31.2\% of adults aged 15 years and older use cigarettes or tobacco and this rate was $27.1 \%$ in $2012(n=14.8){ }^{[1,7]}$ According to WHO, smoking rates in Turkey are $22 \%$ in the adults in $2015 .{ }^{[8]}$ According to OECD 2015 data, Turkey is the third among the European countries, and one among the top ten countries along with China, India, Indonesia, Russia, the US, Japan, Brazil, Bangladesh, and Germany in cigarette consumption (Greece 38\%, France $24.1 \%$, and $23.8 \%$ Turkey). ${ }^{[9]}$

The aim of this study was to investigate the factors related to cigarette smoking, nicotine addiction levels, knowledge, attitudes, and behaviors of the public employees of the Selçuk University.

\section{METHOD}

This study was planned to determine the frequency of tobacco use and the attitudes and behaviors of 37,168 people in Konya Province Public Employees between 2017 and 2018. This is a cross-sectional study. Using the formula, $n=\frac{N \times p \times q \times z_{\alpha}^{2}}{(N-1) \times d^{2}+z_{\alpha}^{2} \times p \times q}$, it was calculated that 3,737 of

37,168 public employees should be reached because the frequency of smoking is $27 \%$ according to the 2012 GATS results. ${ }^{[7,10]}$ Of these public employees, 4,278 are public employees of the Selçuk University. The share of the sample was 430 people, thus 458 Selçuk University public employ- ees are included in this study. With a stratified sample, 458 people were reached from 4278 people by applying rule 9 to 1 . In the academic year 2017-2018, a questionnaire consisting of 39 questions including the factors affecting the use/cessation of tobacco and its products, knowledge, attitudes, and behaviors of the public employees of the Selçuk University was conducted.

Fagerström Test for Nicotine Dependence (FTND): The Turkish adaptation of the questions used in the United States for the classification of smoking status was used. ${ }^{[1]]}$ The smoking individuals were categorized as current smokers, former smokers, occasional smokers, and never smokers (current smokers-individuals who have smoked at least 100 cigarettes during their lives and currently have at least one cigarette per day; former smokers-those who have smoked at least 100 cigarettes during their lifetime and have quit; ever smokers-those who have smoked not more than 100 pcs in their lifetime; and never smokersthose who had never smoked in any way. In order to classify the smokers and the ex-smokers in terms of the gradual change process, the Turkish adaptation of the question team proposed by Prochaska et al. ${ }^{[12]}$ was used. For addiction scoring and grading, the Turkish version of the Fagerström Nicotine Test questions was used.

The FTND is a test developed to determine the level of nicotine addiction and consists of six questions. Scores are given according to the response to each question. This test which was studied for Turkish validity and reliability gave five different results: $0-2$ points is very low, 3-4 points is low, 5 points is moderate, $6-7$ points is severe, and 8-10 points is very severe. ${ }^{[13,14]}$

\section{Statistical Analysis}

Demographic data were analyzed using descriptive statistical methods by using SPSS (Statistical Package for Social Sciences for Windows) 22.0 version. Number, percentage, mean, standard deviation, and minimum and maximum values were used to evaluate the data. A chi-square test was used to examine the comparison of categorical data. A $p$ value of $<0.05$ was considered statistically significant.

\section{RESULTS}

The mean age of 458 (male: $64.6 \%, 296$ individuals; female: $35.4 \%, 162$ individuals) participants was $39.21 \pm 10.26$ years.

The sociodemographic features and smoking-tobacco use characteristics of the university public employees are shown in Table 1.

The frequency of tobacco users or smokers among the university public employees was 147 (32.1\%); of never smok- 
Table 1. The sociodemographic features and characteristics of smoking-tobacco use of the university public employees $(n=458)$

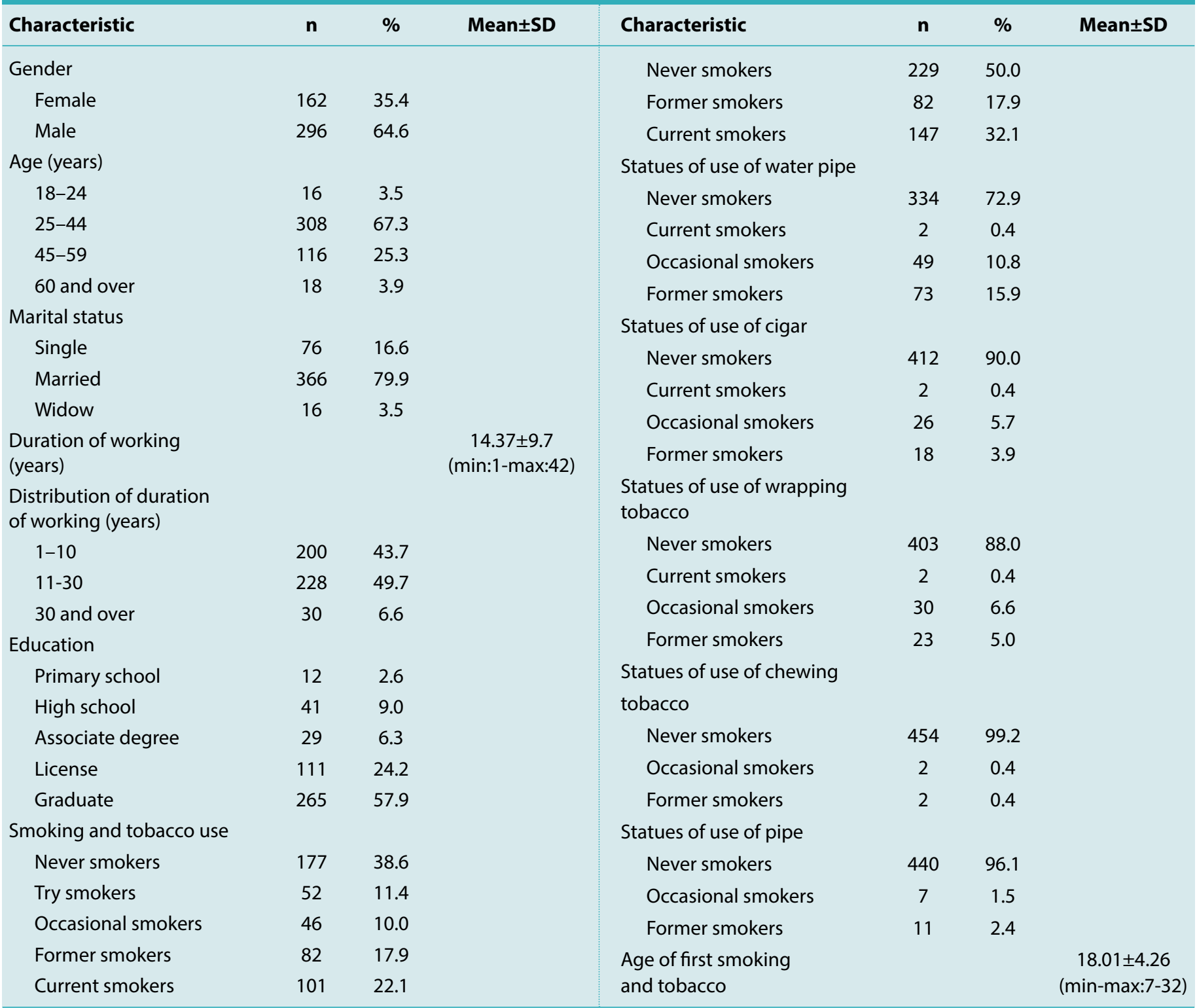

ers 229 (50.0\%); and of former smokers 82 (17.9\%). The frequency of water pipe use was $11.1 \%$, of wrapping tobacco use $7.0 \%$, of cigar use $6.1 \%$, of pipe use $1.5 \%$, and of chewing tobacco use $0.4 \%$ (Table 1 ).

Table 2 shows the distribution of tobacco use and smoking status according to gender, age, and department of university public employees $(n=458)$.

Among university public employees in medicine faculty, the prevalence of tobacco use and smoking in academic staff (research assistant, assistant professor, associate professor, and professor) was 13 (23.2\%) and that of other medical staff (nurse, etc.) was 30 (38.0\%). Among the uni- versity public employees, the prevalence of tobacco use and smoking was found to be $113(38.2 \%)$ in males and 34 $(21.0 \%)$ in females $(p=0.000)$ (Table 2$)$.

Table 3 shows the distribution of only cigarette smoking status according to gender, age, and institutions of the university public employees $(n=458)$.

Among the university public employees, the prevalence of only cigarette smoking was $122(26.6 \%)(98(33.1 \%)$ for men and 26 (16.0\%) for women, difference between genders was statistically significant; $p=0.000$ ) (Table 3 ). In addition, the rate of current smokers was found to be lower in academic staff (research assistant, assistant professor, as- 
Table 2. The distribution of tobacco use and smoking status according to gender, age, and department of the university public employees $(n=458)$

\begin{tabular}{|c|c|c|c|c|c|c|c|c|c|c|}
\hline & \multicolumn{8}{|c|}{ Smoking and tobacco uses } & $\mathbf{X}^{2}$ & $\mathbf{p}$ \\
\hline \multicolumn{11}{|l|}{ Male } \\
\hline Academical staff in other faculty & 81 & 36.5 & 58 & 26.1 & 83 & 37.4 & 222 & 100.0 & $=6.78$ & $=0.148$ \\
\hline Total & 113 & 38.2 & 70 & 23.6 & 113 & 38.2 & 296 & 100.0 & & \\
\hline \multicolumn{11}{|l|}{ Female } \\
\hline Academical staff in medicine faculty & 15 & 71.4 & 4 & 19.1 & 2 & 9.5 & 21 & 100.0 & & \\
\hline \multicolumn{11}{|l|}{ Categorical age } \\
\hline $18-24$ & 9 & 56.3 & 1 & 6.2 & 6 & 37.5 & 16 & 100.0 & & \\
\hline $25-44$ & 166 & 53.9 & 37 & 12.0 & 105 & 34.1 & 308 & 100.0 & & \\
\hline $45-59$ & 49 & 42.2 & 35 & 30.2 & 32 & 27.6 & 116 & 100.0 & & \\
\hline 60 and over & 5 & 27.8 & 9 & 50.0 & 4 & 22.2 & 18 & 100.0 & $=33.33$ & $=0.000$ \\
\hline \multicolumn{11}{|l|}{ Department } \\
\hline Academical staff in medicine faculty & 34 & 60.7 & 9 & 16.1 & 13 & 23.2 & 56 & 100.0 & & \\
\hline Nurse and other medical staff & 40 & 56.6 & 9 & 11.4 & 30 & 38.0 & 79 & 100.0 & $=6.416$ & $=0.170$ \\
\hline Academical staff in other faculty & 155 & 48.0 & 64 & 19.8 & 104 & 32.2 & 323 & 100.0 & & \\
\hline
\end{tabular}

sociate professor, and professor) with 10 (17.9\%) compared to other medical staff (nurse, etc.) 28 (35.4\%) and academic staff in faculties other than medical faculties $84(26.0 \%)$ $(p=0.053)$ (Table 3$)$. In addition, the prevalence of only cigarette smoking in males of other medical staff (nurse, etc.) was statistically higher than the other male employees $(p=0.042)$.

The smoking habits of the university public employees are shown in Table $4(n=122)$.

When the distribution of university public employees according to FTND was evaluated, it was found that $44.4 \%$ (55 individuals) was in very low, 7\% (32 individuals) in low, 2.6\% (12 individuals) in moderate, $12.1 \%$ (15 individuals) in severe, and $8.1 \%$ (10 individuals) in very severe addiction group (Table 4). The mean of first smoking age was $18.01 \pm 4.26$ and the duration of smoking was $18.52 \pm 10.33$ years.

The smoking status of the family and friends of the university public employees is shown in Table 5 .
No smoking was reported in houses of 141 (30.8\%) of university public employees. In the house of 299 (65.3\%), smoking was allowed only at balcony, and in the house of 18 (3.9\%), smoking was reported. In addition, 263 (57.4\%) have no smokers in the house. Parents of $42(9.2 \%)$, spouse of $52(11.4 \%)$, sibling of $42(9.2 \%)$, and son of $8(1.7 \%)$ were smokers. Of the guests who visited the house, 165 (36.0\%) never smoked; 211 (46.1\%) of them claim permission to smoke, 66 (14.4\%) of them smoke at balcony, and 16 (3.5\%) of them smoke at house without permission. In addition, it was detected that $342(74.7 \%)$ of the employees did not smoke in closed areas, 55 (12\%) smoke in the smoking room, and 33 (7.2\%) smoke everywhere.

The knowledge and attitudes of the university public employees and their relatives regarding their smoking behaviors, attempts for smoking cessation, and prohibitions are shown in Table 6.

Although 149 (32.5\%) of the university public employees surveyed answered 'no' in terms of being a role model for 


\begin{tabular}{|c|c|c|c|c|c|c|c|c|c|c|}
\hline & \multicolumn{2}{|c|}{$\begin{array}{c}\text { Never } \\
\text { smokers }\end{array}$} & \multicolumn{2}{|c|}{$\begin{array}{l}\text { Former } \\
\text { smokers }\end{array}$} & \multicolumn{2}{|c|}{$\begin{array}{l}\text { Current } \\
\text { Smokers }\end{array}$} & \multicolumn{2}{|c|}{ Total } & \multirow[b]{2}{*}{$X^{2}$} & \multirow[b]{2}{*}{$\mathbf{p}$} \\
\hline & $\mathbf{n}$ & $\%$ & $\mathbf{n}$ & $\%$ & $\mathbf{n}$ & $\%$ & $\mathbf{n}$ & $\%$ & & \\
\hline \multicolumn{11}{|l|}{ Male } \\
\hline Academical staff in medicine faculty & 19 & 54.3 & 7 & 20.0 & 9 & 25.7 & 35 & 100.00 & & \\
\hline Nurse and other medical staff & 12 & 30.8 & 8 & 20.5 & 19 & 48.7 & 39 & 100.0 & & \\
\hline Academical staff in other faculty & 79 & 35.6 & 73 & 32.9 & 70 & 31.5 & 222 & 100.0 & $=9.92$ & $=0.042$ \\
\hline Total & 110 & 37.2 & 88 & 29.7 & 98 & 33.1 & 296 & 100.0 & & \\
\hline \multicolumn{11}{|l|}{ Female } \\
\hline Academical staff in medicine faculty & 15 & 71.4 & 5 & 23.8 & 1 & 4.8 & 21 & 100.0 & & \\
\hline Nurse and other medical staff & 27 & 67.5 & 4 & 10.0 & 9 & 22.5 & 40 & 100.0 & & \\
\hline Academical staff in other faculty & 74 & 78.7 & 6 & 6.4 & 14 & 14.9 & 94 & 100.0 & $=5.25$ & $=0.262$ \\
\hline Total & 116 & 76.3 & 12 & 7.9 & 24 & 15.8 & 152 & 100.0 & & \\
\hline \multicolumn{11}{|l|}{ Categorical age } \\
\hline $18-24$ & 9 & 56.3 & 2 & 12.5 & 5 & 31.2 & 16 & 100.0 & & \\
\hline $25-44$ & 164 & 53.3 & 61 & 19.8 & 83 & 26.9 & 308 & 100.0 & & \\
\hline $45-59$ & 48 & 41.4 & 37 & 31.9 & 31 & 26.7 & 116 & 100.0 & & \\
\hline 60 and over & 5 & 27.8 & 10 & 55.5 & 3 & 16.7 & 18 & 100.0 & $=18.71$ & $=0.005$ \\
\hline \multicolumn{11}{|l|}{ Department } \\
\hline Academical staff in medicine faculty & 34 & 60.7 & 12 & 21.4 & 10 & 17.9 & 56 & 100.0 & & \\
\hline Nurse and other medical staff & 39 & 49.4 & 12 & 15.2 & 28 & 35.4 & 79 & 100.0 & $=9.32$ & $=0.053$ \\
\hline Academical staff in other faculty & 153 & 47.4 & 86 & 26.6 & 84 & 26.0 & 323 & 100.0 & & \\
\hline Total & 226 & 49.4 & 110 & 24.0 & 122 & 26.6 & 458 & 100.0 & & \\
\hline
\end{tabular}

smoking in society, 309 (67.5\%) answered yes. Of the participants, 298 (65.1\%) gave the correct answer (171) to the question of "what is the number of smoking cessation line of TR ministry of health?" Of the participants, 440 (96.1\%) sup- port smoking ban in closed areas. Although 248 (54.1\%) of the participants supported the ban on smoking in closed areas, 179 (39.2\%) believe that the scope should be expanded. Of the respondents, 130 (28.4\%) answered correctly the question for the start date of the tobacco control law (07-19-2009), which prohibits smoking in public places (Table 6).

\section{DISCUSSION}

In our country and in many countries around the world, various studies have been carried out on the smoking status and affecting factors among the academic staff and university students. The main reason for these studies on university academic staff is that they are role models for the big part of the society.

When the results of the GATS study, which was conducted for the first time in 2008, included information on the use of tobacco and its products, exposure to cigarette smoke, the tendency to quit tobacco and tobacco use, attitudes and perceptions of the public on media and health warnings compared to the 2012 GATS results, comprehensive tobacco control studies in Turkey have achieved significant success over four years. The comparison results show us that the frequency of tobacco use decreased from $31.2 \%$ to $27.1 \%$ in the population over 15 years of age, from $47.9 \%$ to $41.5 \%$ in males, and from $15.2 \%$ to $13.1 \%$ in females. The percentage of daily cigarette smokers decreased from $27.4 \%$ in 2008 to $23.8 \%$ in 2012 and the percentage of occasional smokers decreased from $3.8 \%$ to $3.3 \%$. In our country, tobacco and its products are the most common among 25-34 and 35-44 age groups. The frequency of tobacco use was higher in males (41.5\%) than in females (13.1\%). Of the tobacco users, $23.8 \%$ use tobacco every day (37.3\% of males and $10.7 \%$ of females). The largest share of tobacco users $(94.8 \%)$ use cigarette and only $0.8 \%$ use hookahs. ${ }^{[1,7]}$ In our study, the prevalence of tobacco and cigarette use in university public employees was $32.1 \%$ and the cigarette use frequency was $26.6 \%$ (33.1\% in males, $14.8 \%$ in females), suggesting that tobacco and cigarette use is still a major problem in our country. In addition, dependence 


\begin{tabular}{|c|c|c|}
\hline Characteristic & $\mathbf{n}$ & $\%$ \\
\hline \multicolumn{3}{|l|}{ Fagerström test for nicotine dependence } \\
\hline Very low & 55 & 44.4 \\
\hline Low & 32 & 25.8 \\
\hline Moderate & 12 & 9.6 \\
\hline Severe & 15 & 12.1 \\
\hline Very severe & 10 & 08.1 \\
\hline \multicolumn{3}{|l|}{ Where do you mostly smoke? } \\
\hline At home & 30 & 24.6 \\
\hline In workplace & 50 & 41.0 \\
\hline In car & 08 & 6.6 \\
\hline Outdoor & 16 & 13.1 \\
\hline Anywhere & 18 & 14.7 \\
\hline \multicolumn{3}{|l|}{ Which brand does your smoking? } \\
\hline Domestic brand & 23 & 19.7 \\
\hline Foreign brand & 76 & 62.3 \\
\hline Both of them & 23 & 18.0 \\
\hline \multicolumn{3}{|l|}{ Have you thought about quitting smoking? } \\
\hline No, I didn't think & 25 & 20.5 \\
\hline I didn't make any attempts & 32 & 26.2 \\
\hline I thought, I made an attempt & 65 & 53.3 \\
\hline \multicolumn{3}{|l|}{ Have you tried to quitting smoking? } \\
\hline No & 39 & 32.0 \\
\hline Yes I tried once & 25 & 20.5 \\
\hline Yes I tried so many times & 58 & 47.5 \\
\hline \multicolumn{3}{|l|}{ Did you use a method to quit smoking? } \\
\hline No & 103 & 84.4 \\
\hline $\begin{array}{l}\text { I only used nicotine replacement } \\
\text { therapy }\end{array}$ & 2 & 1.6 \\
\hline $\begin{array}{l}\text { I used nicotine replacement therapy } \\
\text { and smoking cessation medications }\end{array}$ & 7 & 5.7 \\
\hline Others & 10 & 8.2 \\
\hline \multicolumn{3}{|l|}{$\begin{array}{l}\text { How did the smoking prohibition in } \\
\text { closed areas and campaigns } \\
\text { implemented in Turkey affcet your } \\
\text { smoking habit? }\end{array}$} \\
\hline Never affected & 62 & 50.8 \\
\hline Significantly reduced & 54 & 44.2 \\
\hline I stopped smoking at home & 3 & 2.5 \\
\hline Significantly increased & 3 & 2.5 \\
\hline
\end{tabular}

and dependence level are the most important obstacles in the discontinuation of tobacco use. In a study conducted by Altın et al. ${ }^{[15]}$ in 2004, the high dependence level was found to be $25 \%$. In our study, according to FNAT, $70.2 \%$ of the public employees in the university are in very low and low dependency group and $20.2 \%$ in high and very high
Table 5. The smoking status of the family and friends of the university public employees $(n=458)$

\begin{tabular}{lcc} 
Characteristic & $\mathbf{n}$ & $\%$ \\
\hline Smoking status at home & & \\
It is not smoked in house & 141 & 30.8 \\
It is smoked only in balcony & 299 & 65.3 \\
It is smoked in the house & 18 & 3.9 \\
Person smoking at home & & \\
No & 263 & 57.4 \\
Mother & 4 & 0.9 \\
Father & 38 & 8.3 \\
Spouse & 52 & 11.4 \\
Brother & 42 & 9.2 \\
Son & 8 & 1.7 \\
More than one member of family & 51 & 11.1 \\
Smoking status of guests coming home & & \\
No smoking & 165 & 36.0 \\
smoking with permission & 211 & 46.1 \\
Smoking on the balcony & 66 & 14.4 \\
Smoking without permission & 16 & 03.5 \\
Smoking policy in the workplace & & \\
No smoking in closed areas & 342 & 74.7 \\
Smoking in the smoking room & 55 & 12.0 \\
In personal rooms & 23 & 5.0 \\
Smoking everywhere & 33 & 7.2 \\
I dont know & 5 & 1.1 \\
& & \\
\hline
\end{tabular}

dependency group, suggesting that they can quit smoking with an effective smoking counseling service.

The prevalence of smoking was reported to be $7 \%-21 \%$ in students of the dentistry, medicine, pharmacy, and nursing departments according to the study conducted in 2005 by the World Health Organization and the Center for Disease Control and Prevention in 20 European countries. ${ }^{[16]}$ In the study conducted by the Association of Public Health Specialists in cooperation with WHO, US Disease Control and Protection Center, and Ministry of Health in 2008, the prevalence of smoking in general practitioners was found to be $30.5 \%$; in specialist doctors $22.5 \%$; in nurses and midwives 29.5\%; and in health technicians 33.8\% ${ }^{[17]}$ Again, in the study conducted by Association of Public Health Specialists in 2012 in cooperation with WHO, US Centers for Disease Control and Protection Center, and Ministry of Health, smoking prevalence was detected as $23.9 \%$ in general practitioners; $12.7 \%$ in specialist doctors; $21.9 \%$ in nurses and midwives; and $23.5 \%$ in health technicians. ${ }^{[18]}$ When the 2012 data were compared with the 2008 data, it was observed that the prevalence of smoking among health- 


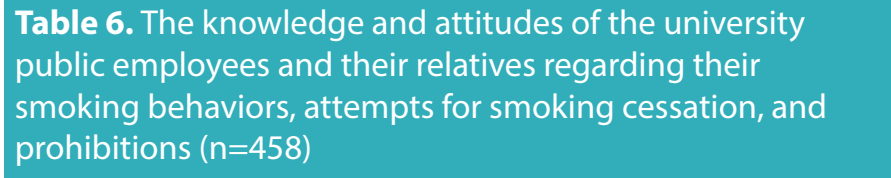

Characteristic $\quad$ n $\%$

Are you a role model in the community

for smoking?

$\begin{array}{lll}\text { No } & 149 & 32.5 \\ \text { Yes } & 309 & 67.5\end{array}$

What is the number of smoking cessation line of TR ministry of health?

$\begin{array}{lcc}112 & 2 & 0.4 \\ 155 & 2 & 0.4 \\ 171 & 298 & 65.1 \\ 181 & 40 & 8.7 \\ 184 & 51 & 11.1 \\ \text { I dont know } & 65 & 14.3\end{array}$

Do you support smoking prohibition

in closed areas?

$\begin{array}{lcc}\text { No } & 18 & 3.9 \\ \text { Yes } & 440 & 96.1\end{array}$

What do you think about the continuation of the smoking prohibition in closed areas implented in Turkey?

Should be removed

Should be loosened

$2 \quad 0.4$

Should be continued

Should be expanded

When did the tobacco control law which prohibits smoking in public places start?

\begin{tabular}{lcc} 
January 3,2006 & 57 & 12.4 \\
May 19,2008 & 131 & 28.6 \\
May 1,2008 & 54 & 11.8 \\
July 19,2009 & 130 & 28.4 \\
I dont know & 86 & 18.8 \\
\hline
\end{tabular}

care workers of TR Ministry of Health decreased significantly. However, in our study, it was found that smoking and tobacco use rates in academic staff (research assistant, assistant professor, associate professor, and professor) were $23.2 \%$ and those of nurses and other health workers were $38 \%$. In our study, when the use of cigarette was evaluated separately, the prevalence of cigarette use was found to be $17.9 \%$ in the academic staff of the faculty of medicine and $35.4 \%$ in the nurses and other health workers, suggesting that the frequency of cigarette use in health workers does not decrease and continues as an important problem. Although the Prime Ministry Circular in 2006 had set targets for health personnel and academic staff, there are very few published research articles on this subject. For this reason, we believe that our study will lead to more comprehensive studies in university academic employees.

In 1998, Tezcan et al., ${ }^{[19]}$ in their study of "Investigation of the Personal Health Behaviors of Academic Staff at Hacettepe University Faculty of Medicine," found that $38 \%$ of the academic staff had never smoked, $15.8 \%$ were former smokers, and $37.2 \%$ were still smokers $(37.9 \%$ in males, $36.3 \%$ in females). The prevalence of smoking was found to be significantly higher in males. In a study conducted by Özkurt et al. ${ }^{[20]}$ in 1996, at the Faculty of Medicine of the Pamukkale University, it was found that 48\% (6.9\% occasionally, $41.1 \%$ every day) of the medical faculty employees were smokers and $14.3 \%$ were former smokers. Tezcan et al., ${ }^{[21]}$ in their review of 22 studies, reported the prevalence of smoking to be $32.6 \%-66.2 \%$ in doctors, $40.3 \%-68.6 \%$ in nurses, and $15.1-36.6 \%$ in medical school students in Turkey.

Sezer et al., ${ }^{[22]}$ in their study in 2001 including academic staff of Sivas Cumhuriyet University Faculty of Medicine and Dentistry, detected that the frequency of smokers was $47.4 \%$ in males and $33.3 \%$ in females. The frequency of everyday smokers was found to be $36.3 \%$ in males and $24.4 \%$ in females. Marakoğlu et al. ${ }^{[23]}$ reported the frequency of smokers was 28.7 (35.6\% in males and $13.4 \%$ in females) in their study including the Selçuk University Faculty of Medicine academic staff. In a study conducted by Karatay et al. ${ }^{[24]}$ (2017) in a public university in Tunceli, $16.5 \%$ of the participants stated that they occasionally smoke and $30.4 \%$ regularly smoke; $10.4 \%$ were found to be exposed to passive smoking at home and $23.9 \%$ at work; $37.6 \%$ of participants were in middle and $16.8 \%$ were in high level of nicotine addiction, and finally, $42.4 \%$ were found to be in the precontemplation stage for smoking cessation and $32.7 \%$ were in the contemplation phase. In addition, it was determined that $10.8 \%$ of the smokers used wrapping tobacco and $89.2 \%$ used package. The results of our study revealed different or similar results with some of the previous studies on tobacco use and smoking frequency. These results suggest that the results are subject to change according to years, sample size, and participation in the study.

According to GATS studies, the use of water pipe decreased (from $2.3 \%$ in 2008 to $0.8 \%$ in 2012). ${ }^{[1,7]}$ In 2010, 645 medical students were included in the study and the prevalence of the use of water pipe was $32.7 \% .{ }^{[25]}$ In our study, the frequency of continuous use of water pipe was $0.4 \%$ and the frequency of occasional use was $10.7 \%$. One of the most important reasons for this is that academic staff members are mostly middle-aged and therefore less likely to go to water pipe cafeterias. In this respect, it is important for 
health workers not to limit tobacco dependence to cigarette smoking and to explain the harms of water pipe use especially for young people.

According to the literature, studies on the use of tobacco other than package use are limited. In a 1993 study, the prevalence of smoking among clinicians in Minnesota was $4.9 \%$ (5.1\% of clinicians use pipe; $2.1 \%$ uses cigars). ${ }^{[26]}$ In a study conducted on 821 health workers in the Izmir province, the frequency of cigar use was found to be $1.3 \%$, of pipe, use $0.5 \%$, and both of cigar and pipe use $0.2 \% .{ }^{[27]}$ In our study, the frequency of continuous cigar users was $0.4 \%$, of occasional cigar users 5.7 , and of occasional pipe users $1.5 \%$ (our results were lower than those of previous studies).

In a study conducted in the medical faculty in 2000 , the frequency of current daily cigarette smokers was $45.6 \%$ in the young population aged $20-24$ and $45 \%$ in the $25-44$ age group. ${ }^{[20]}$ In a prevalence study of 6,000 people in the Eastern Black Sea region, the prevalence of current daily cigarette smokers was found to be $51.4 \%$ in the young population aged $20-29$ and $41.1 \%$ in the $30-49$ age group. ${ }^{[28]}$ In our study, the frequency of current daily cigarette smokers among the young population aged 18-24 years was found to be $31.3 \%$, and it was $26.9 \%$ in the $25-44$ age group, $26.7 \%$ in the $45-59$ age group, and $16.7 \%$ in the group older than 60 years. The prevalence of smoking in the young age group is high and it is important to give smoking quitting supports for these groups.

According to GATS 2012 data, six out of 10 (55.1\%) smokers thought to quit smoking, but only $12.9 \%$ thought they would quit in the next 30 days. Approximately $23 \%$ of smokers thought to quit smoking within the next 12 months, whereas $19.7 \%$ of smokers thought to quit but did not say a specific date. ${ }^{[1]}$ In our study, $53.3 \%$ of the smokers who smoked from the university public employees considered smoking cessation and made any attempt. In addition, $68 \%$ of smokers have tried to quit smoking once or more in their lives but they have failed; we believe that this failure is associated with their psychological states. The most important support in the fight against tobacco should be given to the academic staff who smoke at this point. Having information about the quit smoking process in the period of quit smoking, getting support from health personnel, and eliminating the reasons for restart will result in success. Although measures are taken with "tobacco control programs" in developed countries about the smoking, known to have carcinogenic effects, it is not acceptable for health workers and academic staff who have educative and protective roles in society. The fact that $53.3 \%$ of the health care workers who are still smoking have tried to leave in the past suggests that these people can easily enter the quitting process with the support of behavior and/ or medical treatment.

In a study conducted by Eroğlu in a public hospital in Istanbul in $2013,13 \%$ of 164 participants had no family members who smoke, and $87 \%$ had at least one person who smokes in their families. ${ }^{[29]}$ In a study conducted in the Izmir province with 821 people who are medical staff in 2004, it was found that $27.5 \%$ had no family members who smoke, and $72.5 \%$ had at least one person smoking in their families. ${ }^{[27]}$ In our study, it was determined that $42.6 \%$ of the smokers had at least one family member who smoke, and $57.4 \%$ did not have a smoker in their families.

In addition, $62.3 \%$ of the participants were found to use foreign brand cigarettes. These results are similar to the results of the study performed with 1309 individuals between 2009 and 2010 in Suleyman Demirel University in which frequency of use of foreign brand smoking was determined as $63.3 \% .^{[30]}$

Although $74.7 \%$ of the academic staff participating in the study supported smoking ban in closed areas, we determined that ban on smoking in closed areas and antismoking campaigns in Turkey do not affect $50.8 \%$ of the participants. This shows that smoking ban is not fully implemented in public institutions, especially in hospitals. Moreover, it can be seen obviously that all public institutions, especially hospitals, and managers should make more efforts in this regard. People who work in a health institution and who form a role model for the community should not draw the image of a person who smokes in a building that provides health services to people. Administrators should ensure smoke-free airspace, prevent passive exposure, especially in closed areas, as it is intended by law, and thus protect other people from passive smoking.

It is a correct approach to see academicians and academic staff at universities as role models in tobacco control. However, the results of our study showed that $32.5 \%$ of the employees did not consider themselves to be a role model for smoking and only $65.1 \%$ of respondents answered the phone number of the Ministry of Health cigarette quitline (171) correctly. It is also surprising that only $28.4 \%$ of the participants know that the tobacco control law, which prohibits smoking in public closed areas in Turkey, has been implemented on July 19, 2009. This may be because public employees other than managers and administrators do not know these announcements and the relevant legislation. 


\section{CONCLUSION}

Studies on smoking and tobacco use, which were first conducted in 1998, showed that tobacco and cigarette use continued to be a significant public health problem in university public personnel, health workers, and the general public even though tobacco and cigarette use decreased over the years. We believe that physicians, especially academic staff, have major responsibilities in the fight against tobacco and its products.

\section{Disclosures}

Peer-review: Externally peer-reviewed.

Conflict of Interest: None declared.

Ethics Committee Approval: The study was approved by the Local Ethics Committee.

Authorship Contributions: Concept - K.M.; Design - K.M.; Supervision - K.M.; Materials - K.M.; Data collection \&/or processing - K.M., G.Ü.Ü.; Analysis and/or interpretation - K.M.; Literature search - K.M., G.Ü.Ü.; Writing - K.M., G.Ü.Ü.; Critical review - K.M.

\section{REFERENCES}

1. Global Adult Tobacco Survey (GATS), 2012 Turkey 2012. Turkish Public Health Institution. Available at: https://www.who. int/tobacco/surveillance/survey/gats/report_tur_2012.pdf. Accessed June 27, 2019.

2. WHO Report On The Global Tobacco Epidemic (MPOWER), 2008, WHO, Geneva. Available at: https://www.who.int/tobacco/global_report/2013/en/. Accessed June 27, 2019.

3. World Health Organization. WHO Report on the Global Tobacco Epidemic: Warning about the Dangers of Tobacco. Geneva: World Health Organisation. Available at: http://www.ssuk.org. tr. Accessed June 27, 2019.

4. Bilir N, Çakır B, Dağlı E, Ergüder T, Önder Z. Tobacco Control in Turkey. Available at: http://www.euro.who.int/_data/assets/ pdf_file/0004/98446/E93038.pdf. Accessed June 27, 2019.

5. Gunay T, Pekel O, Simsek H, Sahan C, Soysal A, Kilinc O, et al. Smoking habits and cessation success. What differs among adults and elderly? Saudi Med J 2014;35:585-91.

6. Ministry of Health. Turkey: PIAR Research, Smoking Prevalence among People Over 15. Ankara: 1998.

7. Global Adult Tobacco Survey (GATS), 2012 Turkey 2008. Turkish Public Health Institution. Available at: http://www.halksagligiens.hacettepe.edu.tr/english/GATS_english.pdf. Accessed June 27, 2019.

8. WHO Tobacco Control, 2015 World Health Organization. World Health Statistics 2015. Available at: htpp://www.who. int/whosis/whostat/2015/en/index.html. Accessed June 27, 2019.

9. Education at a Glance 2015. Available at: http://download.eiie.org/Docs/WebDepot/EaG2015_EN.pdf. Accessed June 27,
2019.

10. Sümbüloğlu K, Sümbüloğlu V. Biyoistatistik. 17st edition. Ankara: Hatiboğlu Yayınları; 2016.

11. Prochaska JO, Goldstein MG. Process of smoking cessation. Implications for clinicians. Clin Chest Med 1991;12:727-35.

12. Prochaska JO, Di Clemente Ce. Stages and Process of Self Change of Smoking: toward an integrated model of change. Journal of Consulting and Clinical Psychology 1983;51:390-5.

13. Fagerstrom KO, Heatherton TF, Kozlowski LT. Nicotine addiction and its assessment. Ear Nose Throat J 1990;69:763-5.

14. Uysal MA, Kadakal F, Karşidağ C, Bayram NG, Uysal O, Yilmaz V. Fagerstrom test for nicotine dependence: reliability in a Turkish sample and factor analysis. Tuberk Toraks 2004;52:115-21.

15. Altın R, Kart L, Ünalacak M, Dutkun Y, Örnek T. Prevalence of Smoking and Evaluation of Attitudes Towards Smoking in Medical Faculty Hospital. Kocatepe Medical Journal 2004;5:63-7.

16. Yang T, Yu L, Bottorff JL, Wu D, Jiang S, Peng S, et al. Global Health Professions Student Survey (GHPSS) in Tobacco Control in China. Am J Health Behav 2015;39:732-41. [CrossRef]

17. Association of Public Health Specialists Turkey Public Health Report 2008 http://halksagligiokulu.org/anasayfa/components/com_booklibrary/ebooks/TURKIYE\%20SAGLIK\%20 RAPORU_HASUDER_2012.pdf. Available from: 08.05.2018.

18. Association of Public Health Specialists Turkey Public Health Report 2012 http://halksagligiokulu.org/anasayfa/components/com_booklibrary/ebooks/TURKIYE\%20SAGLIK\%20 RAPORU_HASUDER_2012.pdf. Available from: 08.05.2018.

19. Tezcan S Yardım N. Examination of the Personal Health Behavior of Academic Staff Working in Hacettepe University Faculty of Medicine, 1998.

20. Özkurt S, Bostancı M, Altın R, Özşahin A, Akdağ B. Prevalence of Smoking in the Faculty of Medicine, Nicotine Dependence and Pulmonary Function Tests. Tuberculosis and Thorax Journal 2000;48:140-7.

21. Tezcan S, Yardim N. Prevalence of smoking between the doctors, nurses and medical faculty students at some health facilities in Turkey. [Article in Turkish]. Tuberk Toraks 2003;51:3907.

22. Sezer RE, Marakoğlu K, Sezer H, Marakoğlu i. Smoking Status and Smoking Opinions of Faculty Members of Faculty of Medicine and Dentistry of Cumhuriyet University. Cumhuriyet University Faculty of Medicine Journal 2001;23:25-36.

23. Marakoğlu K, Kutlu R, Sahsivar S. The frequency of smoking, quitting and socio-demographic characteristics of physicians of a medical faculty. West Indian Med J 2006;55:160-4. [CrossRef]

24. Karatay G, Gürarslan Baş N. Status of Active and Passive Smoking, Addiction Level and Stages of Change at Public University Employees. HSP 2018;5:44-50.

25. Poyrazoğlu S, Sarli S, Gencer Z, Günay O. Waterpipe (narghile) smoking among medical and non-medical university stu- 
dents in Turkey. Ups J Med Sci 2010;115:210-6. [CrossRef]

26. Hensrud DD, Sprafka JM. The smoking habits of Minnesota physicians. Am J Public Health 1993;8:415-7. [CrossRef]

27. Erbaycu AE, Aksel N, Çakan A, Özsöz A. Smoking Habit of Health Professionals in Izmir City. Thorax Journal 2004;5:6-12.

28. Can G, Cakirbay H, Topbaş M, Karkucak M, Capkin E. The prevalence of cigarette smoking in the Eastern Black Sea Region. [Article in Turkish]. Tuberk Toraks 2007;55:141-7.
29. Aydoğan Eroğlu S. Health Professionals' Smoking Status and Influencing Factors in a General State Hospital in Istanbul. Istanbul Med J 2013;14:170-4. [CrossRef]

30. Korkmaz M, Ersoy S, Özkahraman Ş, Taşçı E, Orak S, Hikmet Orhan H. Tobacco Products-Alcohol Consunption Status and Approach to Smoking in Students of Suleyman Demirel University. SDU Medical Faculty Journal 2013:20;34-42. 